\title{
In silico molecular and morphological analysis of rice blast resistant gene Pi-ta in Sri Lankan rice germplasm
}

\author{
Suvanthini Terensan ${ }^{1 *}$, H. Nishadi S. Fernando ${ }^{2}$, J. Nilanthi Silva² , S. A. Chandrika N. Perera ${ }^{3}$,
} Nisha S. Kottearachchi ${ }^{4}$ and O. V. D. S. Jagathpriya Weerasena ${ }^{1}$

\begin{abstract}
Background: $P$ i-ta is a major blast resistant gene, introgressed from indica rice varieties. In this study, diversity of the Pi-ta gene of 47 Sri Lankan rice accessions was studied by bioinformatics, and the results were validated with molecular and disease reaction assays. Sequences of rice accessions at the locus Os12g0281300 were retrieved from Rice SNP-Seek Database, and the coding sequence of reference Pi-ta gene of cultivar Tetep (accession no. GQ918486.1) was obtained from GenBank. Comparisons were made at nucleotide, amino acid, and protein structure level, and the 3D models predicted using Phyre2 software were superimposed using TM-align software.

Results: In silico analysis revealed that 10 accessions possessed resistant allele of the Pi-ta gene. The remaining accessions recorded high polymorphism in the leucine-rich domain resulting in 9 allele types, leading to singleamino acid substitutions at 27 different positions including a functional mutation of alanine to serine at the 918th amino acid position. None of the genotypes led to truncations in the amino acid sequence. The in silico analysis results were validated on 23 accessions comprising resistant and susceptible genotypes and another 25 cultivars from Northern Sri Lanka, by molecular assay using YL183/YL87 and YL155/YL87 resistant and susceptible allelespecific markers. Resistance of Pi-ta gene for the causal fungus, Magnaporthe oryzae, was further validated through pathogenicity assay.

Conclusion: The Pi-ta gene, especially the LRD region, revealed significant variations within Sri Lankan rice cultivars leading to high levels of resistance against blast. This information would be highly useful in breeding programmes for resistance against rice blast.
\end{abstract}

Keywords: Amino acid polymorphism, LRD region, Magnaporthe oryzae, Molecular breeding, R genes

\section{Background}

Rice is the staple diet for more than half of the world's population. Rice blast, caused by the fungus Magnaporthe oryzae, is generally considered to be the most devastating rice disease, posing serious threats for cultivations across the world. Changing climatic conditions, and the highly variable nature of the pathogen have resulted in unpredictable and common blast epidemics

\footnotetext{
* Correspondence: suvanthinis@gmail.com

${ }^{1}$ Institute of Biochemistry Molecular Biology and Biotechnology, University of Colombo, Colombo, Sri Lanka

Full list of author information is available at the end of the article
}

failing disease management programmes. The most effective way to achieve durable disease resistance is the utilization of cultivars possessing disease-resistant genes (R genes) in breeding.

To date, 27 blast resistant genes have been cloned and characterized [1]. Among them, the Pi-ta gene is reported to be effective in combating the blast causing fungus [2-4]. This is a single copy gene, clustered at the centromere of chromosome 12 of rice. Pi-ta gene encodes 928 amino acids which contain the nucleotidebinding site (208-527), a conserved internal hydrophobic domain (407-418), leucine-rich domain (586-928),

\section{Springer Open}

() The Author(s). 2021 Open Access This article is licensed under a Creative Commons Attribution 4.0 International License, which permits use, sharing, adaptation, distribution and reproduction in any medium or format, as long as you give appropriate credit to the original author(s) and the source, provide a link to the Creative Commons licence, and indicate if changes were made. The images or other third party material in this article are included in the article's Creative Commons licence, unless indicated otherwise in a credit line to the material. If material is not included in the article's Creative Commons licence and your intended use is not permitted by statutory regulation or exceeds the permitted use, you will need to obtain permission directly from the copyright holder. To view a copy of this licence, visit http://creativecommons.org/licenses/by/4.0/. 
and four potential glycosylation sites (339, 556, 654, 838). The leucine-rich domain (LRD) in Pi-ta differs from the typical leucine-rich repeat (LRR) of other $R$ genes due to the additional leucine repeats compared with LRR. Both LRD and LRR are found in the Cterminal region which is generally involved in the pathogen recognition [5]. Pi-ta / Avr-Pita is a wellstudied ligand/receptor model where Pi-ta protein acts as a receptor, binds elicitor molecule Avr-Pita leading to defense response of the plant. The presence of a single amino acid polymorphism, serine instead of alanine, at the position of the 918th amino acid in the LRD region of the Pi-ta protein impairs the binding recognition with Avr gene of $M$. oryzae leading the pathogen to lose the ability to infect the plant [2]. This unique feature provides an opportunity to investigate the resistant $\mathrm{Pi}$-ta gene in rice germplasm which is highly useful in view of the huge potential of utilizing the Pi-ta gene in managing the devastating blast disease of rice worldwide.

Generally, indica rice cultivars are a rich source of blast resistant genes with $51 \%$ of resistant genes which are already identified [6]. Pi-ta gene has also been introgressed from indica cultivars (Tetep and Tadukan) to other cultivated rice varieties ([7-9]). However, identification of new donors for blast resistance is a prerequisite to improve the germplasm of any country [10], because, specific varieties adopted for variations in cultivation patterns, seasons, etc., are preferred in producing varieties specific to each region [11]. This emphasizes the need to search for donors of specific origin for the management of blast. Sri Lankan rice cultivation is entirely with indica rice varieties, and thus there may be valuable resistant $\mathrm{R}$ gene sources among the cultivated varieties. The experimental screening of $\mathrm{R}$ genes is tedious and costly, but the utilization of bioinformatics tools provides a better option for developing countries to study the availability of resistant genes in a large number of samples with subsequent confirmation by molecular marker-based experiments for potential candidates [12]. Further, proper identification of $\mathrm{R}$ genes in diverse elite germplasm through DNA markers is a crucial step in confirming the precision in the exploitation of $\mathrm{R}$ gene in marker-assisted selection (MAS) in different rice breeding programmes [13].

Identifying the $\mathrm{R}$ genes in the local germplasm will be more useful in identifying suitable resistant cultivars which are also preferred by the consumers. However, the genetic data of the local cultivars are not available in any public domain. This report describes the first attempt of studying the variations of the Pi-ta gene using a combination of assays such as molecular marker analysis, 3D structural modelling, and pathogenicity assay for the Sri Lankan accessions. Accordingly, in the current study, we studied the diversity of Pi-ta gene mainly in the LRD region, in 47 Sri Lankan rice accessions through in silico analysis and the results were confirmed by disease reaction and molecular marker assay. This validated method was applied to detect the resistant $\mathrm{Pi}$-ta gene in 25 preferred cultivars which are commonly cultivated in the Northern Province of Sri Lanka.

\section{Methods \\ In silico analysis \\ Sequence retrieval}

A complete Pi-ta gene sequence (7295 bp) of 47 Sri Lankan rice accessions (enlisted in the supplementary table 4) was retrieved from the Rice SNP-Seek Database of the International Rice Research Institute (https://snp-seek. irri.org/) by giving the following genotype query options; chromosome/ contig number 12, locus position of Pi-ta gene Os12g0281300 which was obtained from Oryzabase (https://shigen.nig.ac.jp/rice/oryzabase/gene/detail/947), and the reference sequence was Nipponbare (japonica).

A complete sequence of wild-type Pi-ta gene (wPi-ta), of Oryza sativa cultivar indica Tetep (GenBank accession number GQ918486.1), was downloaded from GenBank database (https://www.ncbi.nlm.nih.gov/genbank/). The coding sequence of the Pi-ta gene was considered as the region of interest for this analysis. The gene consists of two exons with the lengths of $944 \mathrm{bp}$ and 1845 bp [14], and total length of the coding sequence was $2789 \mathrm{bp}$.

\section{Comparison of nucleotide and amino acid sequences}

Sequence variation of the accessions was studied by comparing the two exons of each accession with the wild-type Pi-ta (wPi-ta) of Tetep exons using Clustal W multiple alignment program in Bioedit Sequence Alignment Editor Version 7.2.5. Nucleotide polymorphisms among aligned sequences were noted.

The ORF finder tool of NCBI was used to derive the open reading frames of the exon sequences with singlenucleotide polymorphisms in the alignment to find out any possible truncations in coding frames. The corresponding amino acid sequences derived from the ORF finder were aligned using Clustal W alignment tool in the Bioedit Sequence Alignment Editor Version 7.2.5 to observe any changes in the amino acid sequences. A pairwise comparison of the retrieved amino acid sequences with the wild-type sequence was made using BLAST2 (for protein) tool at NCBI to analyze the functional equivalence of each amino acid substitutions.

\section{Structure prediction of Pi-ta gene}

The three-dimensional structure of wPi-ta protein was predicted by using Phyre2 server version 2.0 (http:// www.sbg.bio.ic.ac.uk/phyre2/html/page.cgi?id=index). This server scans the annotated proteins in the SCOP 
and PDB databases against the query sequence and builds a model based on ten templates with the highest matches, based on heuristics to maximize confidence, percentage identity, and alignment coverage [15]. The protein structures of Pi-ta gene of the 47 Sri Lankan rice accessions were predicted by generating an array of plausible models and finally, the best model was selected based on the confidence percentage and the percentage of query alignment. The software HHpred 1.51, Psi-pred 2.5, Disopred 2.4, Memsat_SVM, and Poing 1.0 were used for template detection, secondary structure prediction, disorder prediction, transmembrane prediction, and multi-template modelling and ab initio, respectively.

\section{Structure comparison}

In the presence of significant changes among amino acids, structural differences between the Pi-ta protein $3 \mathrm{D}$ structures of each accession with $w P i-t a$ protein was compared. 3D structure of proteins was compared by TM align software (https://zhanglab.ccmb.med.umich. edu/TM-align/) which is an algorithm for sequenceindependent protein structure comparisons [16]. The accuracy of the alignment was determined based on the root mean square deviation (RMSD) and TM score.

\section{Confirmation of in silico analysis by Molecular marker assay}

Based on the results of in silico analysis, 23 out of the initial 47 accessions, representing resistant and susceptible genotypes, were randomly selected for experimental confirmation by an allele-specific PCR assay (Table 4). In addition, the same assay was conducted for 25 cultivars, commonly cultivated in the Northern Province of Sri Lanka. Cultivar Tetep was used as a reference for the assay (Table 5).

DNA of the 23 selected accessions was extracted using PhytoSpin $^{\mathrm{TM}}$ Plant Genomic DNA extraction kit (Ceygen Biotech, Sri Lanka) following the manufacturer's instructions. PCR was performed to screen the presence of disease resistant (wild type) or disease susceptible allele of Pi-ta gene using allele-specific primers, YL 155 (5'AGCAGGTTATAAGCTAGGCC 3')/YL87 (5' CTAC CAACAAGTTCATCAAA 3' for resistant allele and YL183 (5'AGCAGGTTATAAGCTAGCTAT 3')/YL87) for susceptible allele respectively as published by Jia et al. [17]. PCR was carried out in $25 \mu \mathrm{l}$ reactions containing; 1XPCR buffer (Promega), $2.5 \mathrm{mM} \mathrm{MgCl} 2,0.2$ $\mathrm{mM}$ dNTP, $10 \mu \mathrm{M}$ of each primer, $0.06 \mathrm{U}$ of GoTaq DNA polymerase (Promega Corporation, USA), $2 \mu \mathrm{l}$ of DNA. The PCR amplification was performed following the cycle; initial denaturation at $94{ }^{\circ} \mathrm{C}$ for $5 \mathrm{~min}, 35 \mathrm{cy}$ cles of $94{ }^{\circ} \mathrm{C}$ for $30 \mathrm{~s}, 55{ }^{\circ} \mathrm{C}$ for $45 \mathrm{~s}, 72{ }^{\circ} \mathrm{C}$ for 2 min and final extension at $72{ }^{\circ} \mathrm{C}$ for $5 \mathrm{~min}$. The PCR amplicons were separated by gel electrophoresis on $1 \%$ agarose gel in 1XTAE buffer at $60 \mathrm{~V}$ for $1.5 \mathrm{~h}$. Amplicons were visualized by staining with ethidium bromide and exposing to UV trans-illuminator (Gel documentation system, Vilber lourmat, France).

\section{Disease reaction (pathogenicity assay)}

The seeds of the 23 selected accessions and the 25 cultivars commonly cultivated in the Northern Province of Sri Lanka (Tables 4 and 5) were surface sterilized with $70 \%$ ethyl alcohol for $2 \mathrm{~min}$, rinsed in sterile distilled water, then germinated in plastic pots containing sterile soil, and placed in a greenhouse. Each pot contained 25 seeds per accession. Urea $(0.2 \mathrm{~g} / \mathrm{pot})$ was applied to increase vegetative growth, and plants were watered daily. $M$. oryzae culture was incubated at room temperature $\left(25{ }^{\circ} \mathrm{C}\right)$ until sporulation on a specific medium containing agar $(20 \mathrm{~g})$, sucrose $(5 \mathrm{~g})$, and water $(1 \mathrm{l})$. Conidia were harvested 2 weeks after culturing, and the concentration was adjusted to $1 \times 10^{5}$ per ml. A volume of $10 \mathrm{ml}$ of the suspension $(10 \mathrm{ml})$ was inoculated into each pot using an atomizer when the plants were at 4th to 5th leaf stage. After inoculation, pots were kept in a moistened chamber for $48 \mathrm{~h}$ and then transferred to the green house. The degree of disease on each seedling was evaluated 7 days after inoculation based on the Standard Evaluation System (SES) as described by the International Rice Research Institute (IRRI, 2013). Scores identified as $0-3$ were considered to be resistant (R), 4-5 as moderately resistant (MR) and 69 as susceptible (S) as reported by Imam et al. [18]. This was followed by second scoring after a 3-day interval as reported by Shikari et al. [19].

\section{Results}

\section{In silico analysis}

Out of the 47 accessions analyzed, 37 accessions revealed 18 and 21 different single-nucleotide polymorphisms (SNPs) variations in exons 1 and 2 respectively (Supplementary tables 1 and 2), while 10 accessions (Alagusamba, Honderawala, Pachchaiperumal, Podiwee, Pokkali, Race perumal, Samba, Sithaiyan kottai samba, 3210, and BW 295-5) were identical to wPi-ta (Tetep). The detected SNPs did not lead to truncation of the ORFs. Comparison of the resulting amino acid substitutions at 27 different positions along the amino acid length is given in Table 1 . Among them, 9 SNPs were noted in Nucleotide Binding Site (NBS) and 8 in LRD region resulting in 9 different allelic types (denoted as type I-IX in Table 1). The detailed amino acid variations among all the 47 accessions are given in supplementary table 3 .

Allelic types are numbered as I-IX (Accessions, as per the supplementary table 4, belonging to Type I1,9,25,29,30,33,35,39,44,46; Type II-17, 42; Type III$3,4,6,7,11,12,14,15,16,20,21,23,24,26, \quad 37,40,41,47 ; \quad$ Тyре 
Table 1 Schematic representation of positional changes along with the amino acid sequences of 47 Sri Lankan rice accessions compared to wPi-ta (Tetep). The + sign shows the functional similarities of the amino acids and the empty boxes depict the dissimilarity.

\begin{tabular}{|c|c|c|c|c|c|c|c|c|c|c|c|c|c|c|c|c|c|c|c|c|c|c|c|c|c|c|c|}
\hline$A P^{a}$ & 0 & $\stackrel{\infty}{\leftarrow}$ & 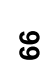 & \% & $\stackrel{\infty}{=}$ & 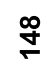 & $\stackrel{\overbrace{}}{\stackrel{\leftrightarrow}{?}}$ & ֶֻ & 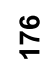 & ల్లి & ঙ্స & $\frac{n}{m}$ & $\stackrel{\circ}{\circ}$ & 용 & g̊ & $\stackrel{8}{\%}$ & F & $\stackrel{\mathscr{q}}{\mathcal{f}}$ & $\overline{6}$ & 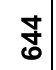 & $\bar{i}$ & $\stackrel{\mathbb{N}}{\mathbf{N}}$ & 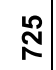 & $\stackrel{0}{\infty}$ & $\begin{array}{c}\widehat{\infty} \\
\infty\end{array}$ & $\bar{\sigma}$ & $\frac{\infty}{\sigma}$ \\
\hline$O A^{b}$ & I & $\mathrm{s}$ & E & A & G & $R$ & $\mathrm{H}$ & $\mathrm{H}$ & D & K & I & $R$ & V & $\mathrm{H}$ & M & $\mathrm{H}$ & 1 & K & A & L & $T$ & $\mathrm{R}$ & $R$ & L & $\mathrm{H}$ & $P$ & A \\
\hline $\mathrm{CA}^{\mathrm{c}}$ & $S$ & $\mathrm{~T}$ & $Q$ & V & $S$ & $S$ & Q & D & V & $R$ & V & K & $\mathrm{F}$ & $Y$ & I & $\mathrm{R}$ & V & $\mathrm{R}$ & $S$ & 1 & $\mathrm{~N}$ & C & C & $\mathrm{F}$ & $\mathrm{N}$ & $\mathrm{L}$ & $S$ \\
\hline BLAST2 & & + & + & & & & & & & + & + & + & + & + & + & & + & & + & + & & & & & + & + & + \\
\hline I & & & & & & & & & & & & & & & & & & & & & & & & & & & \\
\hline II & & & & & & & & & & & & & & & & & & & & & & & & & & & \\
\hline III & & & & & & & & & & & & & & & & & & & & & & & & & & & \\
\hline IV & & & & & & & & & & & & & & & & & & & & & & & & & & & \\
\hline v & & & & & & & & & & & & & & & & & & & & & & & & & & & \\
\hline VI & & & & & & & & & & & & & & & & & & & & & & & & & & & \\
\hline VII & & & & & & & & & & & & & & & & & & & & & & & & & & & \\
\hline VIII & & & & & & & & & & & & & & & & & & & & & & & & & & & \\
\hline IX & & & & & & & & & & & & & & & & & & & & & & & & & & & \\
\hline
\end{tabular}

${ }^{a}$ Amino acid position throughout the total length of Pi-ta protein

${ }^{b}$ Original amino acid position presents in wPi-ta protein

${ }^{\mathrm{C}}$ Changed amino acids in Pi-ta proteins of Sri Lankan rice accessions

IV-2,8,28,31,32,36,43; Type V-5; Type VI-38; Type VII-22; Type VIII-10, 13, 27, 34,19; Type IX-45), where the type I is the wild type (wPi-ta); the positions at which the amino acid substitutions were observed are highlighted in grey for each allelic type.

The maximum number $(n=19)$ of amino acid polymorphisms (APs) was noted in the six accessions: Hodarawala, Karuthaheenati, Mathalowa, Podiheenati, Ranruwan, and A69.1. These accessions shared 97.95\% sequence identity with $w P i-t a$, in blast 2 analysis followed by Mudaligawee and Sayam which revealed 18 and 17 Aps, respectively with $98.06 \%$ sequence identity. The accessions Kuruluwee white and Wir1391 revealed AP in the 918th amino acid position alone. All the 37 accessions displayed alanine to serine substitution at the 918th position, and this was described as a functional mutation determining resistance by altering the binding specificity [5] (Table 2). This mutation is found in the LRD region, directly involving with the pathogen recognition.

There were 8 APs noted in the LRD region including one at position 918 . Four positions $(711,724,725$, and 816 ) had nonequivalent amino acid substitutions. Interestingly, alanine to serine substitution left a plus (+) sign, revealing functional equivalence of the amino acids even though this position confers recognition specificity. Nine templates with the confidence percentage of $>90$ (PDB codes: c4kxfP, c3qflA, c3iz8C, c3iz8A, c1vt4K, c1vt4N, c3iz8G, c4ecnA, and c2a5yB) were selected to model the protein based on heuristics to maximize confidence, percentage identity, and alignment coverage in Phyre 2. Considering the unavailability of resolved 3D structure in the database, structural prediction was carried out for further analysis. Structures of $47 \mathrm{Pi}$-ta genes and wPi-ta of the templates (PDB code)-c2a5yB, c1vt4K, c3iz8C, c3iz8A, c3iz8G, c1vt4N, c3iz8E, c3iz8B, c1vt4P, c1vt4O, c1vt4L, c3iz8D, c3iz8F, c1vt4M, c3iz8H, c1vt4J, c1z6tC, c4kxfP, c5juyB, c1vt4I-were derived with $100 \%$ confidence level, based on homology modelling. Ninety-five percent of the amino acids were modelled at $>90 \%$ confidence level, where it is assumed that the modelled protein adopts the overall fold shown and that the core of the protein is modelled at high accuracy, while 47 residues were modelled by $a b$ initio modelling. The 3D structures of the nine allelic types (Types I to IX: Table 1) revealed amino acid variations leading to alterations in the protein structure resulting in different structural dimensions (Fig. 1).

Structural superimposition of the nine allelic types (Table 1) is presented in Fig. 2a, b.

The results from the superimposition analysis clearly indicated that the variation in amino acid length, resulting in higher Root Mean Square Deviation (RMSD) values (Table 3) even where a single AP is detected. TM score for all the superimpositions were above 0.5 and below 1.0, which assumes that the structures are roughly the same in folds in both SCOP (fold) and CATH (topology) structural classification databases. 
Table 2 Comparison of Pi-ta protein sequences of 47 Sri Lankan rice accessions with wPi-ta (Tetep, GenBank accession number GQ918486.1) using Clustal W, Bioedit 7.2.5. Highlighted in black are the amino acids that contributed to the resistant phenotype due to the absence of the functional mutation at the 918th amino acid position

\begin{tabular}{|c|c|c|c|}
\hline No & Accession name & IRGC No & \\
\hline 0 & wPita & & QGLLSFFLSL PWLLSLPAMH LQPDLMIV \\
\hline 1 & Alagusamba & IRGC $8944-2$ & QGLLSFFLSL PWLLSLPMH LQPDLMIV \\
\hline 2 & Balasuriya & IRGC $66509-1$ & QGLLSFFLSL PWLLSLPSMH LQPDLMIV \\
\hline 3 & Chandina & IRGC $36420-1$ & QGLLSFFLSL PWLLSLPSMH LQPDLMIV \\
\hline 4 & Galawaka handeran & IRGC $31381-1$ & QGLLSFFLSL PWLLSLPSMH LQPDLMIV \\
\hline 5 & Godawel & IRGC 15750 & QGLLSFFLSL PWLLSLPSMH LQPDLMIV \\
\hline 6 & Halsuduheenati & IRGC 15599-1 & QGLLSFFLSL PWLLSLPSMH LQPDLMIV \\
\hline 7 & Heendikwee & IRGC $15587-2$ & QGLLSFFLSL PWLLSLPSMH LQPDLMIV \\
\hline 8 & Herath Banda & IRGC $67630-1$ & QGLLSFFLSL PWLLSLPSMH LQPDLMIV \\
\hline 9 & Honderawala & IRGC $47372-1$ & QGLLSFFLSL PWLLSLPMH LQPDLMIV \\
\hline 10 & Hodarawala & IRGC $67631-1$ & QGLLSFFLSL LWLLSLPSMH LQPDLMIV \\
\hline 11 & Kahatawee & IRGC $12004-1$ & QGLLSFFLSL PWLLSLPSMH LQPDLMIV \\
\hline 12 & Kalu Ilankayan & IRGC $36270-1$ & QGLLSFFLSL PWLLSLPSMH LQPDLMIV \\
\hline 13 & Karutha seenati & IRGC 15515-2 & QGLLSFFLSL PWLLSLPSMH LQPDLMIV \\
\hline 14 & Kotteyaran & IRGC $47383-1$ & QGLLSFFLSL PWLLSLPSMH LQPDLMIV \\
\hline 15 & Kula karupan & IRGC 55328-1 & QGLLSFFLSL PWLLSLPSMH LQPDLMIV \\
\hline 16 & Kurkaruppan & IRGC 15449-1 & QGLLSFFLSL PWLLSLPSMH LQPDLMIV \\
\hline 17 & Kurulu wee (White) & IRGC $66518-1$ & QGLLSFFLSL PWLLSLPSMH LQPDLMIV \\
\hline 18 & Kurulutudu & IRGC $36304-1$ & QGLLSFFLSL PWLLSLPSMH LQPDLMIV \\
\hline 19 & Matholuwa & IRGC $8901-1$ & QGLLSFFLSL PWLLSLPSMH LQPDLMIV \\
\hline 20 & Moddai karupan & IRGC 15465-1 & QGLLSFFLSL PWLLSLPSMH LQPDLMIV \\
\hline 21 & Murunga & IRGC $15428-1$ & QGLLSFFLSL PWLLSLPSMH LQPDLMIV \\
\hline 22 & Mudalige wee & IRGC 74706-1 & QGLLSFFLSL PWLLSLPSMH LQPDLMIV \\
\hline 23 & Muttu Samba & IRGC 36333-1 & QGLLSFFLSL PWLLSLPSMH LQPDLMIV \\
\hline 24 & Nalumoolaikarupan & IRGC 8993-1 & QGLLSFFLSL PWLLSLPSMH LQPDLMIV \\
\hline 25 & Pachchaperumal & IRGC $3474-1$ & QGLLSFFLSL PWLLSLPMH LQPDLMIV \\
\hline 26 & Periya vellai & IRGC $15475-1$ & QGLLSFFLSL PWLLSLPSMH LQPDLMIV \\
\hline 27 & Podi heenati & IRGC $36345-1$ & QGLLSFFLSL PWLLSLPSMH LQPDLMIV \\
\hline 28 & Pannithi & IRGC 51049-1 & QGLLSFFLSL PWLLSLPSMH LQPDLMIV \\
\hline 29 & Podiwee & IRGC 11938-1 & QGLLSFFLSL PWLLSLPMH LQPDLMIV \\
\hline 30 & Pokkali & IRGC $8948-1$ & QGLLSFFLSL PWLLSLPMH LQPDLMIV \\
\hline 31 & Puttu nellu & IRGC 55346-1 & QGLLSFFLSL PWLLSLPSMH LQPDLMIV \\
\hline 32 & Rangoon samba & IRGC $11940-1$ & QGLLSFFLSL PWLLSLPSMH LQPDLMIV \\
\hline 33 & Race perumal & IRGC 55347-1 & QGLLSFFLSL PWLLSLPMH LQPDLMIV \\
\hline 34 & Ranruwan & IRGC $36360-1$ & QGLLSFFLSL PWLLSLPSMH LQPDLMIV \\
\hline 35 & Samba & IRGC 11993-1 & QGLLSFFLSL PWLLSLPMH LQPDLMIV \\
\hline 36 & Sinna sithira kalli & IRGC 51064-1 & QGLLSFFLSL PWLLSLPSMH LQPDLMIV \\
\hline 37 & Sigardis & IRGC 15555-1 & QGLLSFFLSL PWLLSLPSMH LQPDLMIV \\
\hline 38 & Sayam & IRGC $31538-1$ & QGLLSFFLSL PWLLSLPSMH LQPDLMIV \\
\hline 39 & Sithaiyankottai samba & IRGC 50155-1 & QGLLSFFLSL PWLLSLPMH LQPDLMIV \\
\hline 40 & Sudu karayal & IRGC $15348-1$ & QGLLSFFLSL PWLLSLPSMH LQPDLMIV \\
\hline 41 & 2Vellai kollumban & IRGC 15517-1 & QGLLSFFLSL PWLLSLPSMH LQPDLMIV \\
\hline
\end{tabular}


Table 2 Comparison of Pi-ta protein sequences of 47 Sri Lankan rice accessions with wPi-ta (Tetep, GenBank accession number GQ918486.1) using Clustal W, Bioedit 7.2.5. Highlighted in black are the amino acids that contributed to the resistant phenotype due to the absence of the functional mutation at the 918th amino acid position (Continued)

\begin{tabular}{llll}
\hline No & Accession name & IRGC No & \\
\hline 42 & WIR 1391 & IRGC $51605-1$ & QGLLSFFLSL PWLLSLPSMH LQPDLMIV \\
43 & 105 & IRGC $40896-1$ & QGLLSFFLSL PWLLSLPSMH LQPDLMIV \\
44 & 3210 & IRGC $1116950-1$ & QGLLSFFLSL PWLLSLPMH LQPDLMIV \\
45 & A69-1 & IRGC 55305-1 & QGLLSFFLSL LWLLSLPSMH LQPDLMIV \\
46 & BW295-5 & IRGC 63098-1 & QGLLSFFLSL PWLLSLPMH LQPDLMIV \\
47 & H6 & IRGC 157-1 & QGLLSFFLSL LWLLSLPSMH LQPDLMIV
\end{tabular}

\section{Molecular marker assay}

The gel image in Fig. 3a shows the presence of $\mathrm{Pi}$-ta resistant gene in 9 rice accessions including Tetep ( $w P i$ ta). Nine accessions produced amplicons (1042 bp) for the resistant SSR loci YL155/YL87 (Fig. 3a) and 14 accessions which did not produce the amplicons for the above loci, produced amplicons for the susceptible allele; YL183/YL87, at the expected size of 1043 bp (Fig. 3b). The results were consistent with in silico analysis as summarized in Table 4.

Among the 25 tested cultivars from the Northern Province of Sri Lanka, Attakkari, Bw 372, Moddaikaruppan, Suwandal, At 402, Bg 366, Bg 450, and Karuththaheenati did not amplify the resistant SSR loci; YL155/ YL87 (Supplementary figure 1).

\section{Pathogenicity assay}

This assay revealed that among the nine resistant accessions identified in the molecular marker assay, eight were consistent with the results of in-silico analysis except for Race perumal while Karuthaheenati showed resistant reaction out of 14 accessions revealed susceptibility (Table 4). Pathogenicity assay was performed for these two accessions again to validate the results. The same results were obtained in the pathogenicity assay as well. Among the tested cultivars from the Northern Province, 13 scored resistant (R) phenotype, 11 moderately resistant (MR), and one susceptible (S) response. Figure 4 illustrates the two cultivars with the minimum (1 for Bg360) and maximum (6 for Attakari) severity scales observed in the pathogenicity assay performed.

Among the eight cultivars which did not amplify the resistant $w P i$-ta allele, the cultivar Attakari revealed S response in the pathogenicity assay, while cultivars Moddaikaruppan and Suwandal recorded $\mathrm{R}$ response and the remaining five cultivars (Bw372, At402, Karuthaheenati, Bg366, and Bg450) showed MR response (Table 5).

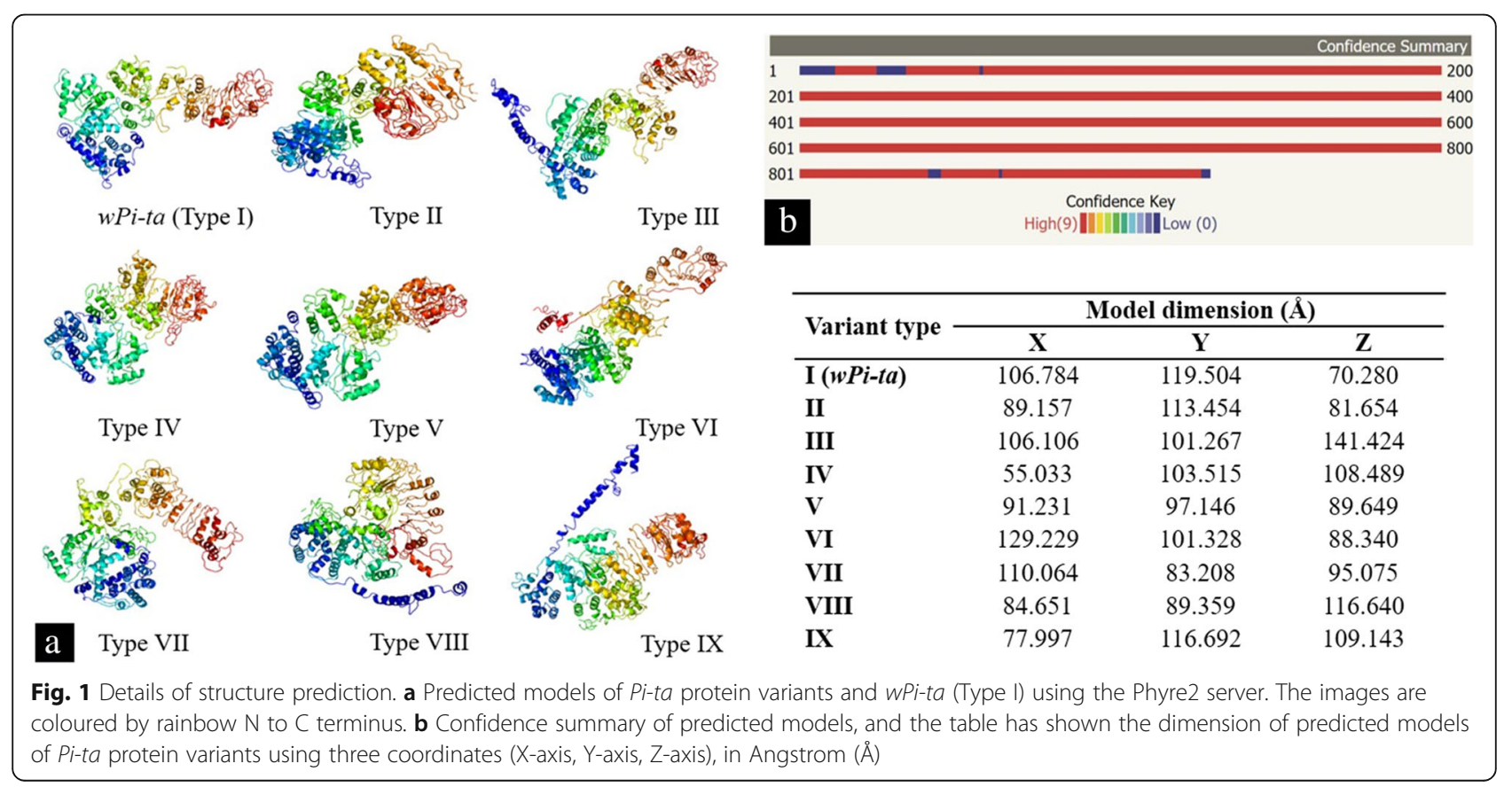


$\mathbf{a}$

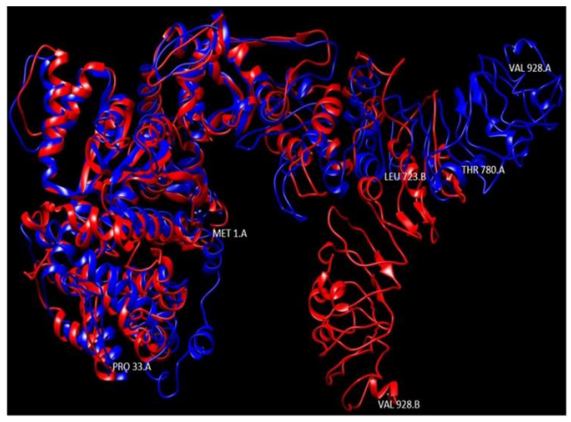

Type II

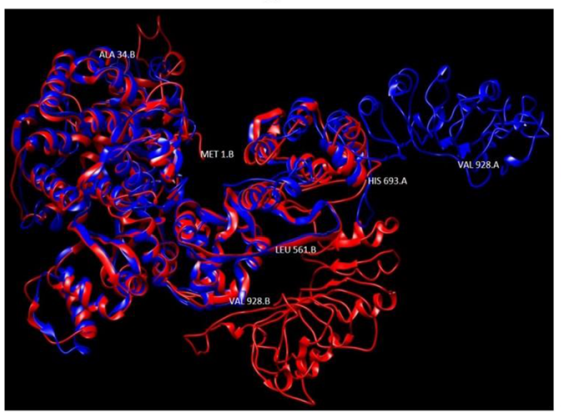

Type IV

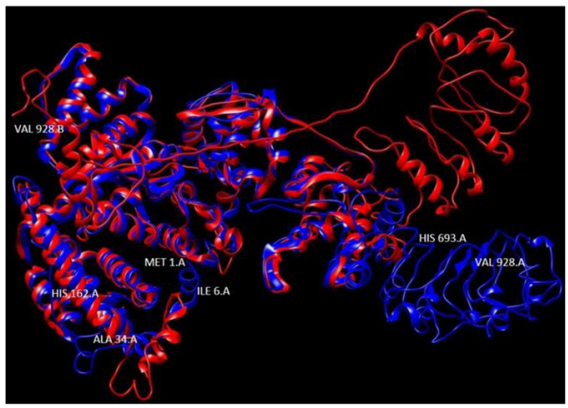

Type VI

b

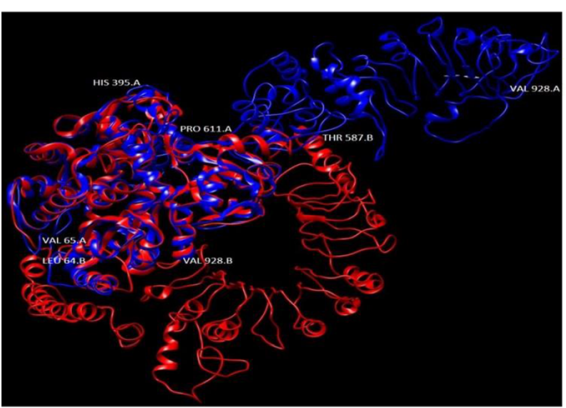

Type VIII

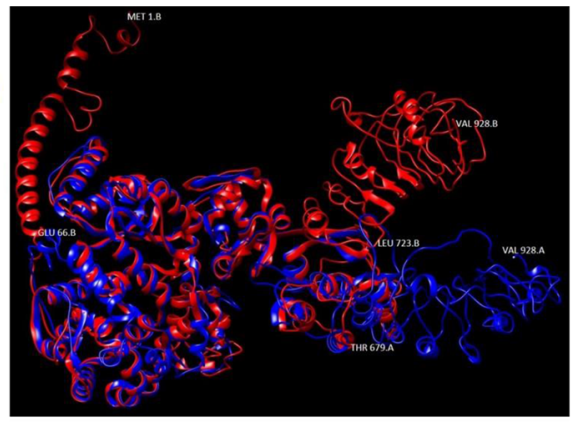

Type III

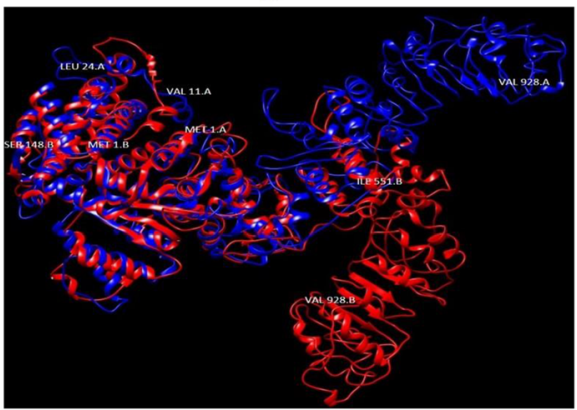

Type V

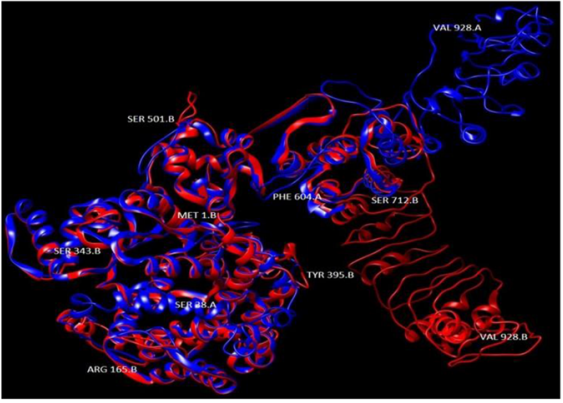

Type VII

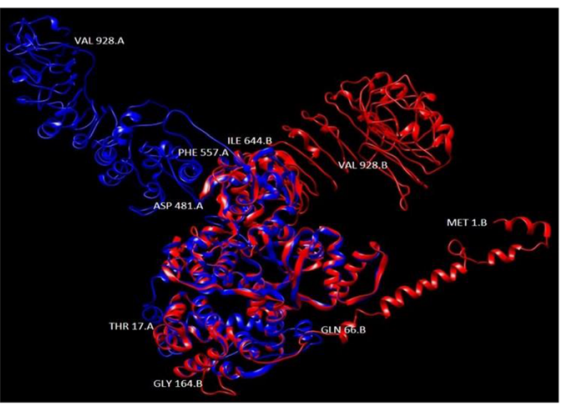

Type IX

Fig. 2 a Superimposition of wPi-ta with the other eight identified variant allelic types (Types II-VII) in TM-align software. b Superimposition of wPi-ta with the other eight identified variant allelic types (Types VIII and IX) in TM-align software

\section{Discussion}

Resistance genes offer the most effective and environmentally safe option for the management of the pathogen [20]. $P i$-ta is a well-studied blast resistant gene [21-23]. Huang et al. [24] studied the molecular evolution of $\mathrm{Pi}$-ta gene in wild rice O. rufipogon and identified two haplogroups, $\mathrm{H} 1$ and $\mathrm{H} 2$, with the amino acid Ala-918 present in $\mathrm{H} 1$ of the LRR domain of Pi-ta gene displaying a close relationship with the resistant phenotype. Yan et al. [25] analyzed the Pi-ta gene diversity and reported 78 polymorphic 
Table 3 The values of root mean square deviation (RMSD) and TM score for superimposed Pi-ta protein variants with wPi-ta

\begin{tabular}{lll}
\hline Pi-ta variant & RMSD & TM score \\
\hline II & 4.32 & 0.67242 \\
III & 3.06 & 0.63381 \\
IV & 3.48 & 0.67963 \\
V & 4.95 & 0.57160 \\
VI & 3.56 & 0.67246 \\
VII & 2.48 & 0.64665 \\
VIII & 4.03 & 0.53159 \\
IX & 2.63 & 0.51643 \\
\hline
\end{tabular}

nucleotide sites which leading to 22 amino acid variations with mutations reported at the 148th, 158th, 176th, and 641st amino acid positions failing to have an impact on the resistance phenotype. Among the $\mathrm{Pi}$-ta variants reported by Wang et al. [4], 105 polymorphic sites were identified with 27 sites resulting in amino acid substitutions, where the higher number of polymorphism was observed in intron regions rather than in exons. The results also suggested that alanine at amino acid position 918 of LRD is critical for the integrity of the Pi-ta protein, and isoleucine at position 6 could result in an insignificant non synonymous change of the $\mathrm{Pi}$-ta protein. A sequence analysis of 1790 accessions was conducted by Wang et al. [26] to characterize Pi-ta, and Pi-ta-independent resistance genes and revealed functional polymorphism at the base position 918 to exhibit resistant phenotype in the pathogenicity assay. Exploitation of valuable sources to obtain resistant $\mathrm{Pi}$-ta gene in local germplasm is an essential yet a challenging task of rice breeders. Identification of major rice blast resistant genes in local elite cultivars improves the value of germplasm sources in rice breeding programs. The current study revealed the Pi-ta gene diversity of the indica rice accessions and cultivars for the exploitation in breeding and management of rice blast disease.

The results of in silico analysis from the current study revealed that ten among the 47 accessions tested to be identical to wPi-ta gene of variety Tetep. Coding nucleotide sequence polymorphism of 47 accessions was compared by Clustal W multiple alignment. The pairwise alignment revealed 10 accessions consist of identical sequences with the wPi-ta gene, while the rest of the accessions displayed nucleotide polymorphisms resulting to nucleotide substitutions leading to 27 different amino acid substitutions in the studied accessions. Mutations in the LRD region is highly significant in pathogen recognition [27], and eight amino acid polymorphisms were noted in the LRD including four nonequivalent amino acid substitutions. Alanine to serine substitution plays a major role in defense response where $\mathrm{Pi}$-ta protein confers recognition specificity with Avr-Pita being an elicitor for hypersensitive reactions [17, 28]. In this

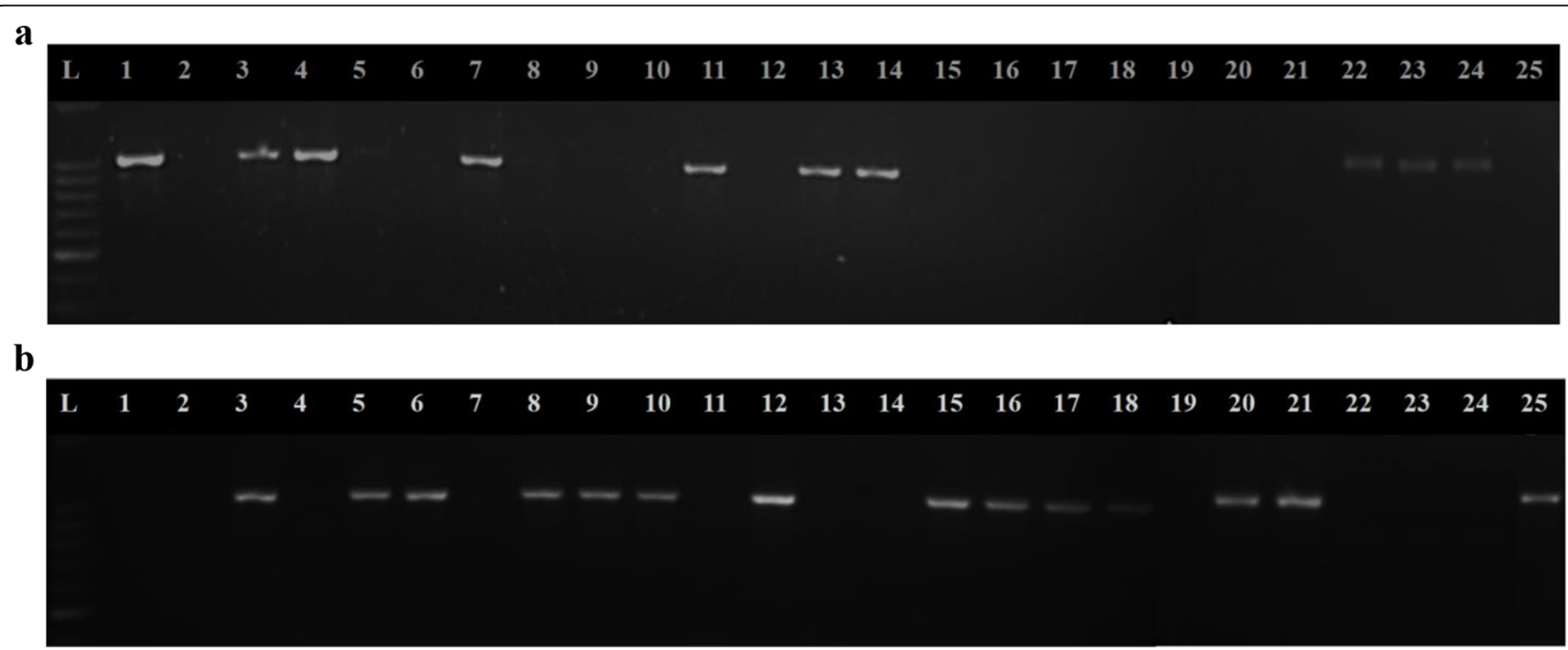

Fig. 3 a The presence or absence of resistant wPi-ta allele using the specific marker YL155/YL87. L: 100 bp ladder, Lane 1: Positive control (Tetep), Lane 2: Negative control, Lane 3: Honderawala, Lane 4: Podiwee, Lane 5: Podiheenati, Lane 6: Periyavellai, Lane 7: Bw 295-5, Lane 8: Sinna sithirakalli, Lane 9: A 69-1, Lane 10: Ranruwan, Lane 11: Pokkali, Lane 12: Mudaligawee, Lane 13: Pachchaperumal, Lane 14: Race perumal, Lane 15: Godawel, Lane 16: Karuthaheenati, Lane 17: Vellaikolumban, Lane 18: 105, Lane 19: Kalullangayan, Lane 20: H6, Lane 21: Sigardis, Lane 22: Samba, Lane 23: Alagusamba, Lane 24: Sithayakottai samba, Lane 25: Kahatawee. $\boldsymbol{b}$ The presence of the 918th mutation in Pi-ta gene using the specific marker YL183/YL87. L: 100 bp ladder, Lane 1: Positive control (Tetep), Lane 2: Negative control, Lane 3: Podiheenati, Lane 4: Podiwee, Lane 5: Kalullangayan, Lane 6: Periyavellai, Lane 7: Bw 295-5, Lane 8: Sinna sithirakalli, Lane 9: A 69-1, Lane 10: Ranruwan, Lane 11: Pokkali, Lane 12: Sigardis, Lane 13: Pachchaperumal, Lane 14: Race perumal, Lane 15: Godawel, Lane 16: Karuthaheenati, Lane 17: Vellaikolumban, Lane 18: 105, Lane 19: Honderawala, Lane 20: H6, Lane 21: Kahatawee, Lane 22: Samba, Lane 23: Alagusamba, Lane 24: Sithayankottai samba, Lane 25: Mudaligawee 
Table 4 Overview of the results for the assays conducted to evaluate the presence of Pi-ta gene in Sri Lankan rice accessions (PGRC — Plant Genetic Resources Institute of Sri Lanka; $R$ resistant, $S$ susceptible; ' + ' represents the presence and '-' represents the absence of amplicons in the specific PCR assays).

\begin{tabular}{|c|c|c|c|c|c|c|}
\hline Accession name & Accession no. & In silico & Severity scale & Disease reaction status & YL155/YL87 & YL183/YL87 \\
\hline Alagusamba & IRGC 8944-2 & $\mathrm{R}$ & 0 & $R$ & + & - \\
\hline Podiwee & IRGC 11938-1 & $\mathrm{R}$ & 1 & R & + & - \\
\hline H6 & IRGC 157-1 & S & 5 & MR & - & + \\
\hline Race perumal & IRGC 55347-1 & $\mathrm{R}$ & 6 & S & + & - \\
\hline BW 295-5 & IRGC 63098-1 & $\mathrm{R}$ & 0 & $\mathrm{R}$ & + & - \\
\hline Samba & IRGC 11993-1 & $\mathrm{R}$ & 0 & R & + & - \\
\hline Pachchaiperumal & IRGC 3474-1 & $\mathrm{R}$ & 1 & R & + & - \\
\hline Honderawala & IRGC 67631-1 & $\mathrm{R}$ & 3 & R & + & - \\
\hline Pokkali & IRGC 8948-1 & $\mathrm{R}$ & 2 & $\mathrm{R}$ & + & - \\
\hline A69-1 & IRGC 55305-1 & S & 5 & $\mathrm{MR}$ & - & + \\
\hline Periyavellai & IRGC 15475-1 & $S$ & 6 & S & - & + \\
\hline Kahatawee & IRGC 12004-1 & S & 7 & S & - & + \\
\hline Karuthaheenati & IRGC 15515-2 & $S$ & 0 & R & - & + \\
\hline Sigardis & IRGC 15555-1 & S & 4 & MR & - & + \\
\hline 105 & IRGC 40896-1 & S & 5 & MR & - & + \\
\hline Godawel & IRGC 15750-1 & S & 5 & MR & - & + \\
\hline Sinna sithirai kalli & IRGC 51064-1 & S & 4 & $\mathrm{MR}$ & - & + \\
\hline Vellaikolumban & IRGC 15517-1 & S & 5 & MR & - & + \\
\hline Podiheenati & IRGC 36345-1 & $S$ & 4 & MR & - & + \\
\hline Mudaligawee & IRGC 74706-1 & $S$ & 7 & S & - & + \\
\hline Kaluilangayan & IRGC 36270-1 & $S$ & 6 & S & - & + \\
\hline Ranruwan & IRGC 36360-1 & $S$ & 5 & $\mathrm{MR}$ & - & + \\
\hline Sithayankottai samba & IRGC 50155-1 & $\mathrm{R}$ & 2 & $\mathrm{R}$ & + & - \\
\hline
\end{tabular}

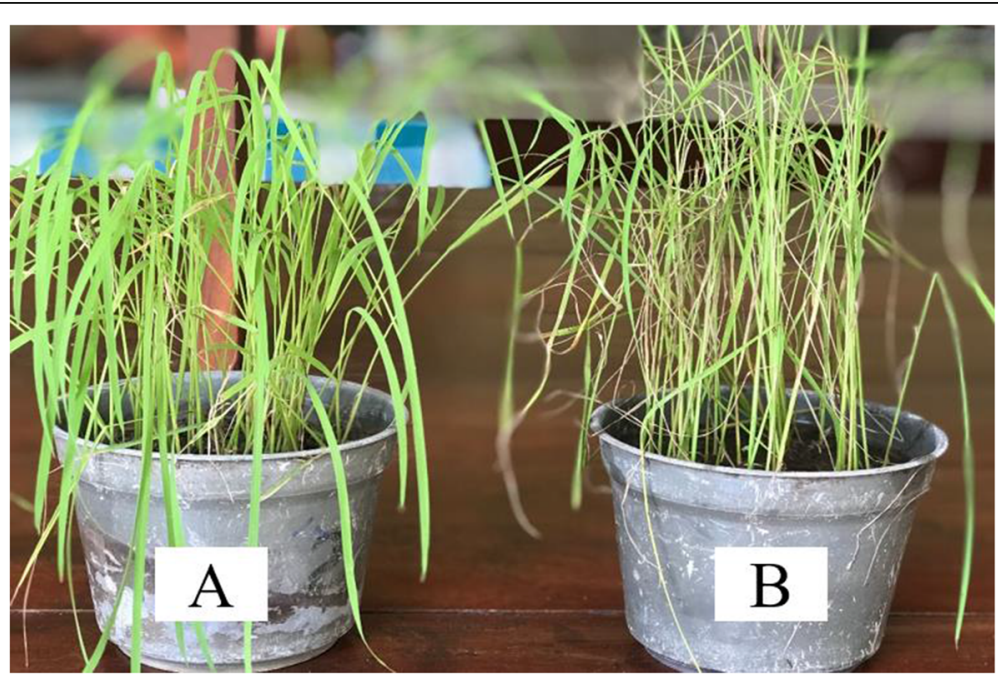

Fig. 4 Seedlings of rice cultivars after 14 days of inoculation of M. oryzae conidia. Bg 360 (A) and Attakari (B) recorded severity scales 1 and 6 respectively 
Table 5 List of 25 cultivars from the Northern Province of Sri Lanka and their response in the pathogenicity assay (KN, Kilinochchi; MU, Mullaitheevu; MA, Mannar; VA, Vavuniya; JFN, Jaffna; '+' represents the presence and '-' represents the absence of amplicon in the specific PCR assays)

\begin{tabular}{|c|c|c|c|c|}
\hline \multirow[t]{2}{*}{ Cultivar } & \multirow[t]{2}{*}{ District } & \multicolumn{2}{|c|}{ Disease symptom } & \multirow{2}{*}{$\begin{array}{l}\text { YL155 } \\
\text { YL87 }\end{array}$} \\
\hline & & Severity scale & Status & \\
\hline $\mathrm{Bg} 360$ & $\mathrm{KN}, \mathrm{MU}, \mathrm{VA}, \mathrm{MA}, \mathrm{JAF}$ & 1 & $\mathrm{R}$ & + \\
\hline At 362 & $\mathrm{KN}, \mathrm{MU}, \mathrm{VA}$ & 1 & $\mathrm{R}$ & + \\
\hline $\mathrm{Bg} 358$ & $\mathrm{KN}, \mathrm{MU}, \mathrm{VA}, \mathrm{MA}$ & 3 & $\mathrm{R}$ & + \\
\hline $\mathrm{Bg} 406$ & $\mathrm{KN}, \mathrm{VA}, \mathrm{MA}$ & 5 & MR & + \\
\hline At 308 & $\mathrm{KN}, \mathrm{MU}, \mathrm{VA}, \mathrm{MA}$ & 2 & $\mathrm{R}$ & + \\
\hline $\mathrm{Bg} 300$ & $\mathrm{KN}, \mathrm{MU}, \mathrm{VA}, \mathrm{MA}, \mathrm{JAF}$ & 5 & MR & + \\
\hline Attakari & $\mathrm{KN}, \mathrm{MU}, \mathrm{VA}$ & 6 & S & - \\
\hline Moddaikaruppan & $\mathrm{KN}, \mathrm{MU}, \mathrm{JAF}$ & 0 & $\mathrm{R}$ & - \\
\hline Suwandal & $\mathrm{KN}, \mathrm{VA}$ & 1 & $\mathrm{R}$ & - \\
\hline Bw 372 & $\mathrm{KN}$ & 5 & MR & - \\
\hline Bw 367 & $M U, V A, M A$ & 1 & R & + \\
\hline At 353 & $\mathrm{MU}$ & 2 & $\mathrm{R}$ & + \\
\hline $\mathrm{Bg} 250$ & $M U, M A$ & 4 & $\mathrm{MR}$ & + \\
\hline At 402 & $\mathrm{MU}$ & 2 & MR & - \\
\hline Pachchaiperumal & $M U, J A F$ & 2 & $\mathrm{R}$ & + \\
\hline Karuthaheenati & $\mathrm{MU}$ & 0 & MR & - \\
\hline Bg 352 & VA, MA & 2 & $\mathrm{R}$ & + \\
\hline Bg 366 & VA & 1 & MR & - \\
\hline $\mathrm{Bg} 450$ & VA, MA & 0 & MR & - \\
\hline Ld 365 & MA & 2 & R & + \\
\hline Co10 & $\mathrm{KN}, J \mathrm{AF}, \mathrm{MU}$ & 5 & $\mathrm{MR}$ & + \\
\hline Bg 369 & KN. MU & 1 & R & + \\
\hline Bw 351 & $\mathrm{KN}$ & 4 & MR & + \\
\hline Bg 251 & $\mathrm{KN}, \mathrm{VA}, \mathrm{MA}$ & 5 & MR & + \\
\hline Bg 94-1 & $M U, M A$ & 2 & R & + \\
\hline
\end{tabular}

study, 37 accessions were revealed to have this mutation in the LRD region.

The Phyre2 server produced a set of potential 3D models of $\mathrm{Pi}$-ta protein based on alignment to known protein structures in the PDB database. The pipeline involved detecting sequence homologues with PSI-Blast; predicting secondary structure and disorder with Psi-pred and Disopred; constructing a hidden Markov model (HMM) of the sequence based on the homologues detected; constructing 3D models of the protein based on the alignments between the HMM of the sequence and the HMMs of known structures; modelling insertions and deletions using a loop library, a fitting procedure (cyclic coordinate descent), and a set of empirical energy terms; modelling of amino acid side chains using a rotamer library from Roland Dunbrack's laboratory; and the server's own implementation of a fast graph-based approach (R3) to optimize the choice of rotamer for each side chain while trying to avoid steric clashes, the top model (if sufficiently confident) submitted for binding site prediction by 3DLigandSite, transmembrane helix, and topology prediction by memsat-svm. The predicted structures of the studied allelic variants (Types II-IX) varied significantly from the wild type (Type I), even with a single mutation (for the type II) at the amino acid position 918. The impact of this specific mutation at amino acid position 918 has been reported previously [2]. However, in the current study, it has been shown that the mutations at the other positions also contributed to structural changes. This was evident in two types, namely Types XIII and IX, where mutations were observed in 19 positions. All except two mutations were observed at the same positions in both types. Even though the variations between these two types are very low, both exhibited significant structural variations.

RMSD scores, a measure of accuracy when comparing different models from a particular dataset, from the 
structural superimposition were consistent with the number of mutations and confirmed the mutation effect on the structure of the resulting protein. Since, the LRD region was involved with the binding to Avr protein of the pathogen, substitutions in the region may make differences in the binding ability [29].

The allele-specific YL155/YL87 and YL183/YL87 primer pairs were selected specifically to differentiate resistant and susceptible genotypes, respectively by amplifying the region of functional gene and mutation at the 918th amino acid position with the same reverse primer. These results were consistent with the in silico analysis facilitating the use of findings to detect the resistant Pi-ta gene in rice cultivars as a validated method. The pathogenicity assay revealed that out of 14 susceptible accessions revealed from the in silico and molecular marker assays, four with the severity scale of 6 and above (Periyavellai, Kahatawee, Mudaligawee, and KaluIlangayan) were highly infected with blast, while the remaining ten were moderately resistant. These results indicated that even though they were susceptible with respect to Pi-ta gene in the in silico analysis, the degree of resistance might vary slightly, due to the influence of other blast resistant genes. But those susceptible accessions amplified the resistant allele for YL183/YL8. Similar results were observed by Jayawardana et al. [30] where some resistant varieties (Bg 300, Bg 348, Ptb33) lack the functional Pi-ta $(w P i-t a)$ gene. The results derived from the in silico analysis were consistent with the resistant phenotype and DNA marker-based molecular screening. As a result, these accessions identified to be resistant can be used as a source of Pi-ta gene for future gene pyramiding work for rice blast resistance. The results of the validation trial with local germplasm clearly indicated the resistant response of the cultivars possessing the wPi-ta allele, while the study further revealed the presence of other genes that might be responsible for resistance in cultivars which did not contain the Pi-ta gene.

\section{Conclusions}

In silico analysis of sequence variations of the Pi-ta gene in Sri Lankan rice varieties revealed that some cultivars contain resistant Pi-ta alleles as similar to that of Tetep, the donor rice variety of the Pi-ta gene. Protein modelling revealed the lack of truncation in the amino acid sequence of the Pi-ta protein but revealed variations in the amino acid sequence, especially in the LRD region, resulting from the single-nucleotide polymorphisms of the Pi-ta gene. Molecular marker assay in detecting the resistant and susceptible Pi-ta alleles and the pathogenicity assay confirmed the validity of the information derived from the in silico analysis. The ten accessions with resistant $P i-t a$ alleles identified in the present study would be useful genetic resources for future breeding programmes. The involvement of genes other than Pi-ta in blast resistance should also be studied. A detailed research on such sources would also be extremely useful in breeding rice for resistance to blast disease.

\section{Supplementary Information}

The online version contains supplementary material available at https://doi. org/10.1186/s43141-021-00239-7.

Additional file 1: Supplementary figure 1. The presence of resistant wPi-ta allele using the specific marker YL155/YL87. L: 100bp ladder, Lane 1: Positive control (Tetep), Lane 2: Negative control, Lane 3: Bg 360, Lane 4: At 362, Lane 5: Attakari, Lane 6: Moddaikaruppan, Lane 7: Bg 358, Lane 8: Suwandal, Lane 9: Bw 372, Lane 10: Bg 406, Lane 11: Pachchaiperumal, Lane 12: At 308, Lane 13: Bg 300, Lane 14: At 402, Lane 15:

Karuthaheenati, Lane 16: Ld 365, Lane 17: Bg 366, Lane 18: Bg 94-1, Lane 19: Bg 251, Lane 20: Co10, Lane 21: Bg 369, Lane 22: Bw 351, Lane 23: Bg 352, Lane 24: Bg 250, Lane 25: Bw 367, Lane 26: At 353, Lane 27: Bg 450

Additional file 2: Supplementary table 1. The presence of mutation in the exon 1 of Pi-ta gene in 47 Sri Lankan rice accessions

Additional file 3: Supplementary table $\mathbf{2}$. The presence of mutation in the exon 2 of Pi-ta gene in 47 Sri Lankan rice accessions

Additional file 4: Supplementary Table 3. Summary of mutation in the Pi-ta protein of 47 Sri Lankan rice accessions

Additional file 5: Supplementary table 4. List of 47 Sri Lankan rice accessions deposited in Rice SNP-Seek Database of the International Rice Research Institute

\section{Acknowledgements}

We appreciate the assistance of Regional Rice Research station, Paranthan, Sri Lanka, especially, Mr. S. Sivanesan for coordinating the seed collection and the Plant Genetic Resource Centre, Sri Lanka for providing Sri Lankan rice accessions and staff of Pathology division of the Regional Rice Research and Development Center, Bombuwala, Sri Lanka in conducting disease reaction tests.

\section{Authors' contributions}

All the authors read and approved the manuscript for submission. ST designed the concept, performed the experiments, and initially drafted the manuscript. NK and JW interpreted and supervised the experimental works and also the correction of the manuscript. NF and NS contributed in the experimental works of pathogenicity assay evaluation and CP assisted for manuscript writing and correction. The authors read and approved the final manuscript.

\section{Funding}

This work was funded by the University Grants Commission, Sri Lanka under the scheme of grants for University teachers for higher studies.

Availability of data and materials Not applicable

\section{Declarations}

Ethics approval and consent to participate Not applicable

Consent for publication

Not applicable

\section{Competing interests}

The authors declare that there are no conflicts of interest.

\section{Author details}

${ }^{1}$ Institute of Biochemistry Molecular Biology and Biotechnology, University of Colombo, Colombo, Sri Lanka. ${ }^{2}$ Regional Rice Research and Development 
Centre, Bombuwala, Sri Lanka. ${ }^{3}$ Department of Agricultural Biology, Faculty of Agriculture, University of Peradeniya, Peradeniya 20400, Sri Lanka. ${ }^{4}$ Department of Biotechnology, Faculty of Agriculture and Plantation Management, Wayamba University of Sri Lanka, Makandura, Sri Lanka.

Received: 23 June 2021 Accepted: 1 September 2021

Published online: 21 October 2021

\section{References}

1. Yadav MK, Aravindan S, Ngangkhan U, Raghu S, Prabhukarthikeyan SR, Keerthana U (2019) Blast resistance in Indian rice landraces: genetic dissection by gene specific markers. PLoS ONE 14(1):e0211061 https://doi. org/10.1371/journal.pone.0211061

2. Bryan GT, Wu KS, Farrall L, Jia Y, Hershey HP, McAdams SA, Faulk KN, Donaldson GK, Tarchini R, Valent B (2000) A single amino acid difference distinguishes resistant and susceptible alleles of the rice blast resistance gene. Pi-ta. Plant Cell 2(11):2033-2045 https://doi.org/10.2307/3871103

3. Jia Y (2009) Determination of resistance spectra of the Pi-ta and Pi-k genes to U.S. races of Magnaporthe oryzae causing rice blast in a recombination inbred line population. Plant Dis 93(6):639-644 https://doi.org/10.1094/PDIS93-6-0639

4. Wang X, Jia Y, Shu QY, Wu D (2008) Haplotype diversity at the Pi-ta locus in cultivated rice and its wild relatives. Phytopathology 98(12):1305-1311 https://doi.org/10.1094/PHYTO-98-12-1305

5. Jia Y, McAdams SA, Bryan GT, Hershey HP, Valent B (2000) Direct interaction of resistant gene and avirulent gene products confers rice blast resistance. EMBO J 19(15):4004-4014 https://doi.org/10.1093/emboj/19.15.4004

6. Sharma TR, Rai AK, Gupta SK, Vijayan J, Devanna BN, Ray S (2012) Rice blast management through host-plant resistance: retrospect and prospects. Agric Res. 1(1):37-52

7. Kiyosawa S (1967) Inheritance of resistance of the rice variety Pi No. 4 to blast. Theor Appl Genet 17(3):165-172 https://doi.org/10.1270/jsbbs1951.1 7.165

8. Moldenhauer KAK, Lee FN, Norman RJ, Helms RS, Well RH, Dilday RH, Rohman PC, Marchetti MA (1990) Registration of 'Katy' rice. Crop Sci 30(3): 747-748 https://doi.org/10.2135/cropsci1990.0011183X003000030065x

9. Seonghee $\mathrm{L}$, Jia SCY, Olsen KM, Caicedo AL (2009) Evolutionary dynamics of the genomic region around the blast resistance gene Pi-ta in AA genome Oryza species. Genetics 183:1315-1325

10. Shikari AB, Rajashekara H, Khanna A, Gopala-Krishnan S, Rathour R, Singh UD, Sharma TR, Prabhu KV, Singh AK (2014) Identification and validation of rice blast resistance genes in Indian rice germplasm. Indian J Genet 74(3): 286-299 https://doi.org/10.5958/0975-6906.2014.00846.3

11. Miah G, Rafii MY, Ismail MR, Puteh AB, Rahim HA, Asfaliza R, Latif MA (2013) Blast resistance in rice: a review of conventional breeding to molecular approaches. Mol Bio Rep 40(3):2369-2388 https://doi.org/10.1007/s11033012-2318-0

12. Srivastava $D$, Shamim MD, Kumar M, Mishra A, Pandey $P$, Kumar D, Yadav $P$, Siddiqui MH, Singh KN (2017) Current status of conventional and molecular inventions for blast resistance in rice. Rice Sci 24(6):299-321 https://doi. org/10.1016/j.rsci.2017.08.001

13. RoyChowdhury $M$, Jia $Y$, Jackson $A$, Jia $M H$, Fjellstrom $R$, Cartwright RD (2012) Analysis of rice blast resistance gene $\mathrm{Pi}-\mathrm{z}$ in rice germplasm using pathogenicity assays and DNA markers. Euphytica 184(1):35-46 https://doi. org/10.1007/s10681-011-0481-3

14. Sallaud C, Lorieux M, Roumen $E_{1}$ Tharreau $D$, Berruyer $R$, Svestasrani $P$ Garsmeur O, Ghesquiere A, Notteghem JL (2003) Identification of five new blast resistant genes in highly blast resistant rice variety IR64 using a QTL mapping strategy. Theor Appl Genet 106(5):794-803 https://doi.org/10.1 007/s00122-002-1088-9

15. Kelley LA, Mezulis S, Yates CM, Wass MN, Sternberg MJE (2015) The Phyre2 web portal for protein modeling, prediction and analysis. Nature protocols 10(6):845-858 https://doi.org/10.1038/nprot.2015.053

16. Zhang YJ, Skolnick (2005) TM-align: a protein structure alignment algorithm based on TM-score. Nucleic Acids Res 33(7):2302-2309 https://doi.org/10.1 093/nar/gki524

17. Jia Y, Bryan GT, Farrall L, Valent B (2003) Natural variation at the Pi-ta rice blast resistance locus. Phytopathology. 93(11):1452-1459

18. Imam J, Alam S, Mandal NP, Variar M, Shukla P (2013) Molecular screening of identification of blast resistance genes in North east and Eastern Indian rice germplasm (Oryza sativa L.) with PCR based markers. Euphytica 196(2): 199-211 https://doi.org/10.1007/s10681-013-1024-x

19. Shikari AB, Khanna A, Gopala-Krishnan S, Singh UD, Rathour R, Tonapi V, Sharma TR, Nagarajan M, Prabhu KV, Singh AK (2013) Molecular analysis and phenotypic validation of blast resistance genes Pita and Pita2 in landraces of rice (Oryza sativa L.). Indian J Genet 73(2):131-141 https://doi.org/10. 5958/j.0975-6906.73.2.020

20. Sharma TR, Rai AK, Gupta SK, Vijayan J, Devanna BN, Ray S (2012) Rice blast management through host-plant resistance: retrospect and prospects. Agric Res 1(1):37-52 https://doi.org/10.1007/s40003-011-0003-5

21. Ramkumar G, Prahalada GD, Hechanova SL, Vinarao R, Jena KK (2015) Development and validation of SNP-based functional codominant markers for two major disease resistance genes in rice (O. sativa L.). Molecular Breeding. 35(6):1-1

22. Jia Y, Bryan GT, Farrall L, Valent B (2004) Natural variation at the Pi-ta rice blast resistance locus. Phytopathology. 93(11):1452-1459

23. Mishra P, Polder G, Vilfan N (2020) Close range spectral imaging for disease detection in plants using autonomous platforms: a review on recent studies. Curr Robot Reports. 1(2):43-48

24. Huang C-L, Hwang S-Y, Chiang Y-C, Lin T-P (2008) Molecular evolution of the Pi-ta gene resistant to rice blast in wild rice (Oryza rufipogon). Genetics. 179(3):1527-1538

25. Yan WA, Zhao JM, Zhang LX, Ping WA, Wang SW, Hui WA et al (2016) Analysis of the diversity and function of the alleles of the rice blast resistance genes Piz-t, Pita and Pik in 24 rice cultivars. J Integrat Agri. 15(7): 1423-1431

26. Wang XU, Fjellstrom R, Jia Y, Yan WG, Jia MH, Scheffler BE et al (2010) Characterization of $\mathrm{Pi}$-ta blast resistance gene in an international rice core collection. Plant Breeding. 129(5):491-501

27. McHale L, Tan X, Koehl P, Michelmore RW (2006) Plant NBS-LRR proteins: adaptable guards. Genome Biol 7(4):212 https://doi.org/10.1186/gb-20067-4-212

28. Jia Y, Zhou E, Lee S, Bianco T (2016) Co-evolutionary dynamics of rice blast resistance gene Pi-ta and Magnaporthe oryzae avirulence gene AVR-Pita 1. Phytopathology 106(7):676-683 https://doi.org/10.1094/PHYTO-02-16-0057RWW

29. Yoshida K, Miyashita NT (2009) DNA polymorphism in the blast disease resistance gene Pita of the wild rice Oryza rufipogon and its related species. Genes Genet Syst 84(2):121-136 https://doi.org/10.1266/ggs.84.121

30. Jayawardana WAD, Jayasekera GAU, Wijesundera RLC, Dissanayake DMN, Sooriyapathirana SDSS, Weebadde CK, Perera KLNS, Gunapala KRD, Hettige P (2014) Evaluation of DNA markers linked to blast resistant genes, Pikh, Pit (p), and Pita for parental selection in Sri Lankan rice breeding. Trop Agric Res 26(1):82-93

\section{Publisher's Note}

Springer Nature remains neutral with regard to jurisdictional claims in published maps and institutional affiliations.

\section{Submit your manuscript to a SpringerOpen ${ }^{\circ}$ journal and benefit from:}

- Convenient online submission

- Rigorous peer review

- Open access: articles freely available online

- High visibility within the field

- Retaining the copyright to your article

Submit your next manuscript at $>$ springeropen.com 